\title{
Coplanar Waveguide Fed Compact Wide Circular-Slotted Antenna for Wi-Fi/WiMAX Applications
}

\author{
M. Samsuzzaman, ${ }^{1}$ T. Islam, ${ }^{1}$ N. H. Abd Rahman, ${ }^{1}$ M. R. I. Faruque, ${ }^{2}$ and J. S. Mandeep ${ }^{1}$ \\ ${ }^{1}$ Department of Electrical Electronic and Systems Engineering, Universiti Kebangsaan Malaysia, Malaysia \\ ${ }^{2}$ Institute of Space Science (ANGKASA), Universiti Kebangsaan Malaysia (UKM), 43600 Bangi, Selangor, Malaysia \\ Correspondence should be addressed to M. Samsuzzaman; sobuzcse@eng.ukm.my
}

Received 23 October 2013; Accepted 24 December 2013; Published 25 February 2014

Academic Editor: Rezaul Azim

Copyright @ 2014 M. Samsuzzaman et al. This is an open access article distributed under the Creative Commons Attribution License, which permits unrestricted use, distribution, and reproduction in any medium, provided the original work is properly cited.

A coplanar waveguide (CPW) fed printing and wide circular slotted, dual band antenna for Wi-Fi/WiMAX applications are presented. The antenna mainly encompasses a ground with a wide circular slot in the centre, a rectangular feeding strip, and two pairs of symmetric planar inverted L (SPIL) strips connecting with the slotted ground. The tuning effects of the rectangular patch, ground size, and SPIL strips to the resonance and matching condition are examined by HFSS and the prototype is fabricated and measured. The simulation and experimental results show that the antenna has an impedance bandwidth with $-10 \mathrm{~dB}$ reflection coefficients $600 \mathrm{MHz}(3.26-3.86 \mathrm{GHz}$, lower band) and $1040 \mathrm{MHz}(5.02-6.26 \mathrm{GHz}$, upper band), which can cover both the Wi-Fi 5.2/5.5/5.8 GHz and WiMAX 3.3/3.5/3.7/5.8 GHz bands. Moreover, a stable omnidirectional radiation pattern and average peak gain for lower band $3.23 \mathrm{~dB}$ and upper band $5.93 \mathrm{~dB}$ have been achieved, respectively.

\section{Introduction}

Due to the snowballing demand for high speed internet access in the world where wireless local area networks (WLAN) cannot reach, Wireless Fidelity (Wi-Fi) and the worldwide interoperability for microwave access (WiMAX) technology have therefore been established as a substitute to provide better and long range wireless broadband services. By incorporating both these (Wi-Fi and WiMAX) technology, service providers can provide high speed internet. On the other hand, the present research activity of the multiple or broadband operation and miniaturized size for current antenna has become one of a highly competitive topic and is mounting superbly, because of rapid development of modern wireless communication system technique. Now the microstrip patch antennas have been one of the most popular antennas in modern wireless communication systems as they have several desirable attributes, such as a lowprofile planar configuration, a light weight, a simple design principle, and a low fabrication cost [1-4]. Various antennas that integrate both Wi-Fi (2.4/5.2/5.5/5.8) and WiMAX $(2.3 / 2.5 / 3.3 / 3.5 / 3.7 / 5.8)$ have been studied. Among them, planar slot antenna [5-15] and monopole antenna [16-21], in which the latter has been subject of many recent studies of wideband and multiband designs.

Microstrip-fed slot antenna [6] with dimension of $30 \mathrm{~mm}$ $\times 35 \mathrm{~mm}$ composed of a rectangular and a trapezoid slot was studied. To induce triple-resonant mode operation at 2.4, 3.5, and $5.5 \mathrm{GHz}$, a pair of symmetrical horizontal stripes was loaded into a rectangular slot antenna; however, this compact design was unable to cover the lower full WiMAX band. Therefore to cover fully the entire WLAN/WiMAX operating bands [7], a slot-ring antenna with a capacitive coupled patch that exhibited quadruple resonant modes was considered. To generate pentaresonant modes, a triangular split-ring resonator slot antenna [5] and a rectangular slot antenna that was loaded with two slits [8] have been developed. Integration of the lowest three resonant modes yields lower operating band, within the bands of interest with a wide $10 \mathrm{~dB}$ bandwidth of up to $75 \%$, supporting WiMAX $2.3 / 2.5 / 3.5 \mathrm{GHz}$ and WLAN $2.4 \mathrm{GHz}$ operations. In addition to that, the corresponding upper operating band also exhibited a broad $10 \mathrm{~dB}$ bandwidth between 18 and 35\%, suitable for WiMAX 5.7 GHz and WLAN 5.2/5.8 GHz applications. However, the 
TABLE 1: Optimized antenna parameter (mm).

\begin{tabular}{lcccccccc}
\hline$L$ & $W$ & $R$ & $L 1$ & $W 1$ & $L 2$ & $L 3$ & $L 4$ \\
\hline 40 & 30 & 14 & 17 & 4 & 6.12 & 12 & 5 \\
\hline$L 6$ & $L 7$ & $L 8$ & $L 9$ & $W 2$ & $W 3$ & $C P W g$ & \\
\hline 10.39 & 6.99 & 9 & 2 & 1 & 5.5 & 0.8 \\
\hline
\end{tabular}

dimensions of these three CPW fed slot antenna shapes as reported in $[5,7,8]$ were between $35 \mathrm{~mm} \times 40 \mathrm{~mm}$ and $50 \mathrm{~mm}$ $\times 50 \mathrm{~mm}$. A dimension of $61 \mathrm{~mm} \times 51.5 \mathrm{~mm}$ antenna has been reported [9] where a pair of parasitic strips introduced to achieve an operating bandwidth of $108.7 \%$. A parasitic $\mathrm{U}$ shaped open stub [10] and a trapezoidal ground [22] are also used in the design of the antenna for WLAN/WiMAX applications. A CPW fed dual wideband antenna formed by a triangular monopole and a U-shaped monopolies are acquired [20]. A conducting triangular section for dual band operation and a multiband inverted $L$ monopolies with zigzag wire [19] has been mentioned to deliver dual band characteristics to cover the $2.4 / 5.2$ and $5.8 \mathrm{GHz}$ WLAN bands. A dual broadband slot antenna is narrated, in which the two wide resonant frequencies were achieved by using a U-shaped strip inset in the centre of the slot antenna of dimensions $75 \mathrm{~mm} \times 75 \mathrm{~mm}$ on a substrate of relative permittivity 4.7 and thickness $0.8 \mathrm{~mm}$. The dual-band WLAN dipole antenna [13] is reported that fabricated on an FR4 substrate with dimensions $12 \mathrm{~mm} \times 45 \mathrm{~mm}$ and uses an internal matching circuit to cover the three WLAN bands properly. A new wideband circularly polarized square slot antenna with a CPW feed composed of two arc-shaped and inverted $L$ grounded strips around opposite and mirror corners of the square slot [23]. But they are all complicated in configuration to reduce the antenna applications.

In this paper, a dual band resonant antenna for WiFi/WiMAX applications is proposed, which is fed by a CPW. The antenna mainly comprises a ground with a big circular slot in the centre, rectangular feeding strip as radiating patch, and introducing two pair of symmetrical planar inverted Lshaped strips connecting the ground. Compared to those designs shown in the literature, not only the antenna has better performance of interference suppression but also compact size, large bandwidth, and high gain. An experimental prototype of the proposed antenna design was fabricated and measured, validating the design concept. The measurements show agreement between the simulated and measured results, all of which make the designed antenna appropriate for WiFi/WiMAX application.

\section{Antenna Design Structure}

Figure 1 shows the geometrical layout of the proposed CPW fed dual band planar slot antenna with symmetric inverted two pair of $L$ strips. The basic antenna structure is a rectangular patch with a dimension of $L X W$ fabricated on one side of a single layer low cost and easy-acquirement epoxy resin fibre FR4 substrate with relative permittivity $\left(\varepsilon_{r}\right) 4.55$, substrate thickness $(h) 1.6 \mathrm{~mm}$, and loss tangent 0.02 . The

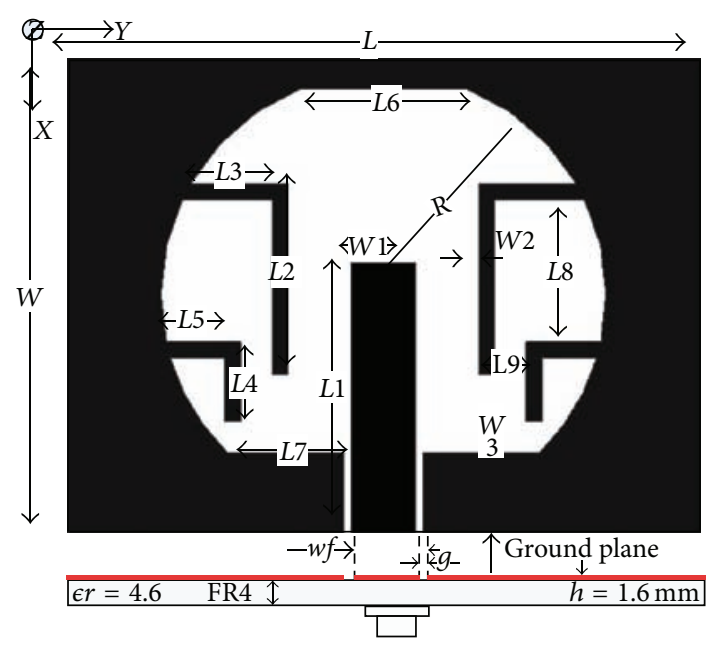

FIGURE 1: Proposed antenna geometric layout.

antenna structure is based on a wide-circular-slotted ground, two pairs of SPIL's in the circular slot with the shorter end connecting with the ground, and it is excited by a $50 \Omega \mathrm{CPW}$ feeding line with a signal strip width of $W 1$ and a gap distance $\mathrm{g}$ between the strip and the coplanar ground. The SPILs are applied to achieve the three band performances with sufficient $-10 \mathrm{~dB}$ impedance bandwidths. A rectangle is taken as overall design and then cutting a circular slot in the middle of the rectangle. In the lower portion a CPW fed a rectangular transmission line is inserted for excitation. Moreover, for generating resonance for Wi-Fi/WiMAX application, two pairs of symmetrical strips are inserted into the slotted area. The optimal geometrical parameters of the proposed antenna are obtained by using finite element method based simulation software HFSS. The optimal dimensions are given in Table 1. Photograph of the fabricated proposed antenna is shown in Figure 2.

\section{Design Procedure and Parametric Studies Based on Simulation}

The design evolution and parametric studies of the proposed antenna were dependent on the finite element method based electromagnetic high frequency structure simulator HFSS. This simulator can envisage the initial characteristics of the antenna without the need for real prototype and measurement.

3.1. Design Evolution. The basic structure of the proposed antenna was modified from a simple CPW-feed planar 


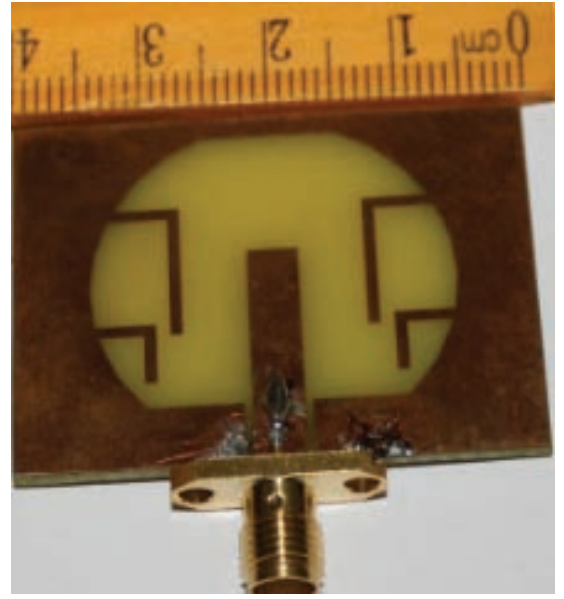

FIGURE 2: Antenna prototype.

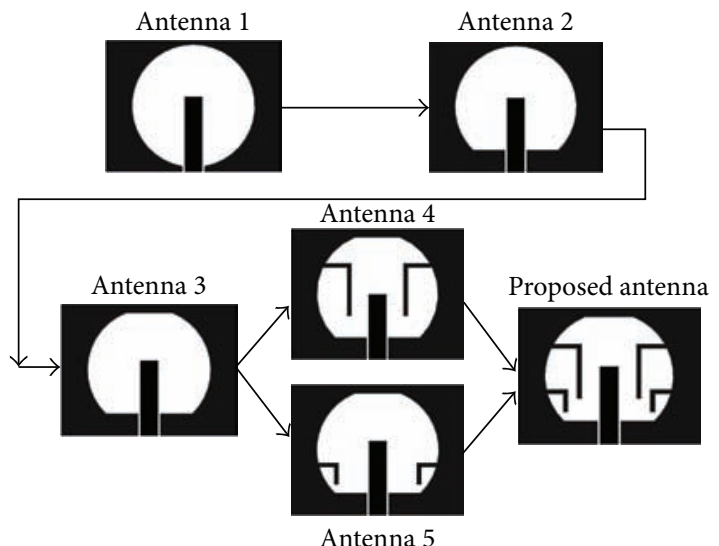

Figure 3: Design evolution procedure of the proposed antenna.

antenna (Antenna 1) which is shown in Figure 3. The motivation for using the strips in the slotted area was to create resonance and widen the impedance bandwidth [24].

Base on its corresponding return loss which is shown in Figure 4 Antenna 1 initially excited no resonance. Antennas 2 and 3 excite $f 2$ and $f 3$ resonance. Antenna 4 excites upper big resonance $(f 2, f 3)$, demonstrating a wide $10 \mathrm{~dB}$ bandwidth at $\sim 3.5 \mathrm{GHz}$. Antenna 4 excites $f 1$ resonance. Combining the two techniques that were used in antennas 4 and 5 caused the proposed antenna to exhibit a dual band with two wide bandwidths, FL (lower band) and FU (upper band), operating from 3.19 to $3.88 \mathrm{GHz}$ and $4.93-6.06 \mathrm{GHz}$, respectively.

3.2. Parametric Studies. Figures 5(a) and 5(b) depicts the simulated return loss of parameters $L 2$ and $L 4$, respectively, of the symmetrical pair of strips that was loaded onto the ground plane. Here a diminishing $f 1$ is observed when decreasing $L 2$ or $L 4$, whereas an increasing $L 2$ or $L 4$ adverse effect on the impedance matching of $f 2$ and $f 3$. Optimum impedance matching can be achieved by setting $L 2=14 \mathrm{~mm}$

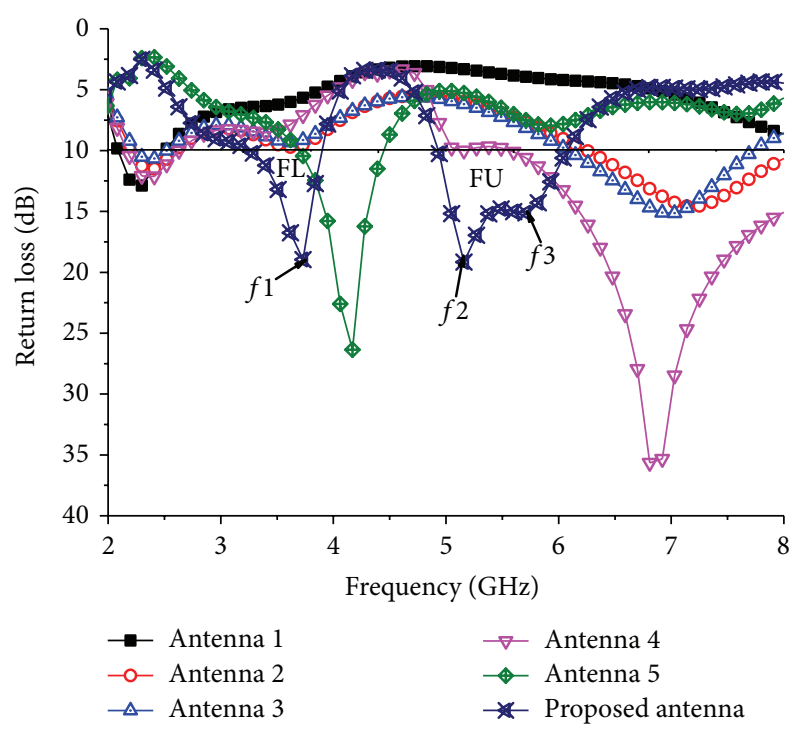

FIGURE 4: Simulated return loss of all prototype antennas and proposed antenna.

and $L 4=5.5 \mathrm{~mm}$. Figure $6(\mathrm{a})$ shows the return loss variation of parameter $W 3$ on the below side of the ground plane. By increasing this $W 3$, it can be observed that resonance $f 1$ is increasing and $f 2$ and $f 3$ are diminishing. On the other hand by decreasing $W 3$ both frequencies $(f 1, f 2$, and $f 3$ ) are decreasing.

Figure 6(b) shows the reflection coefficient variation of CPW gap $g$. When the value of $g$ is increasing, the resonance $f 1, f 2$, and $f 3$ are decreasing. On the other hand, by decreasing the gap, resonance $f 1$ is shifted and $f 2$ and $f 3$ are decreasing. Optimum impedance matching can be achieved by setting $W 3=4.5 \mathrm{~mm}$ and $g=0.8 \mathrm{~mm}$. Figure 7 states that the return loss variation of parameter $L 1$ of the protruding stub and that of both $f 2$ and $f 3$ are highly sensitive to tuning of $L 1$, such that a slight deviation resulted in an 


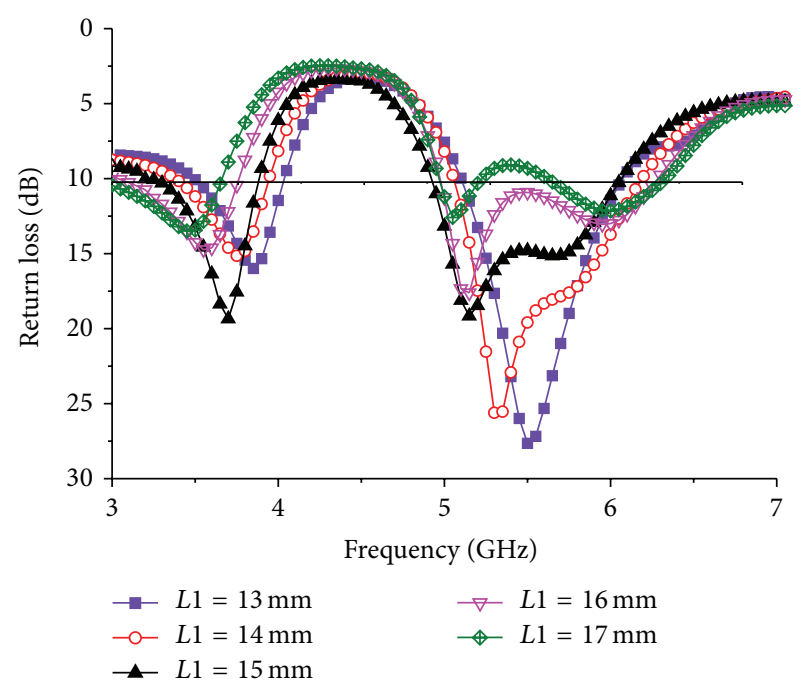

(a)

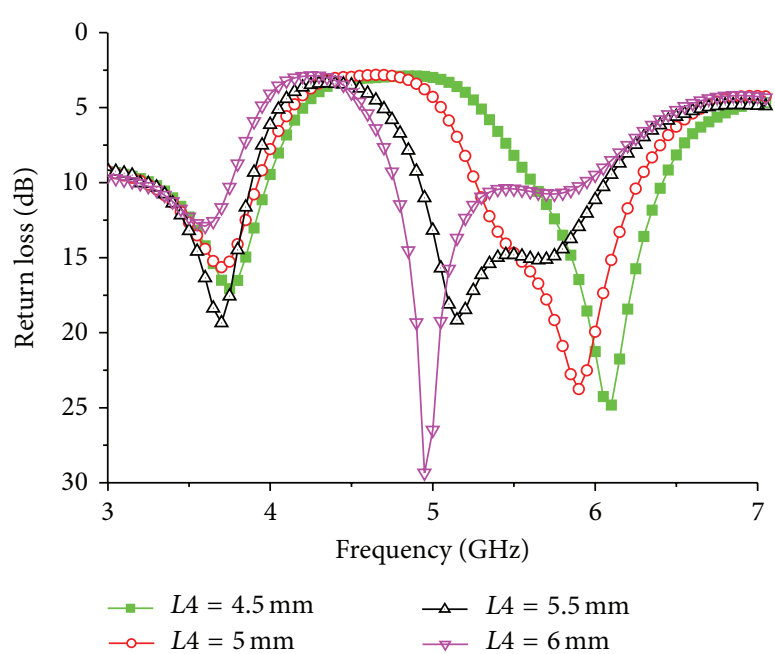

(b)

FIGURE 5: Parametric studies of symmetric slit long (a) $L 1$ (b) $L 4$.

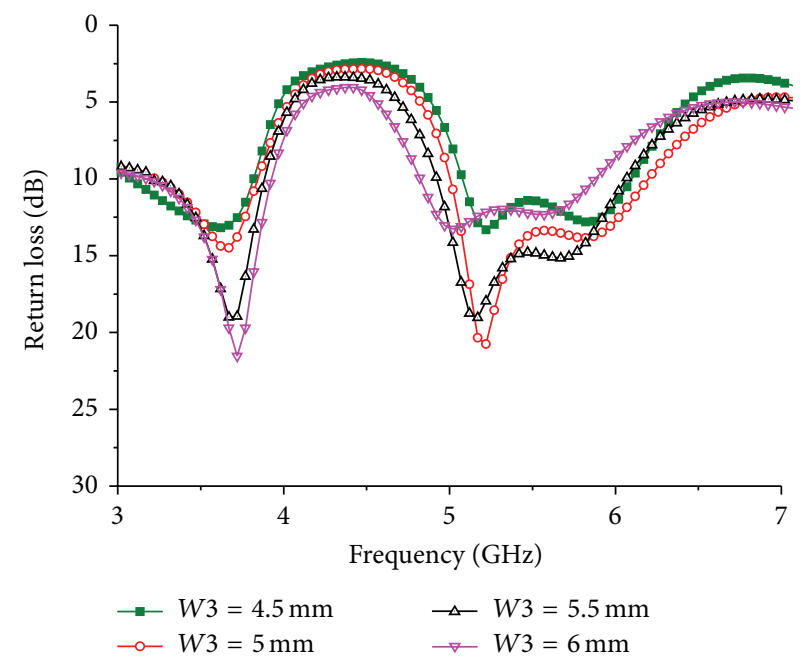

(a)

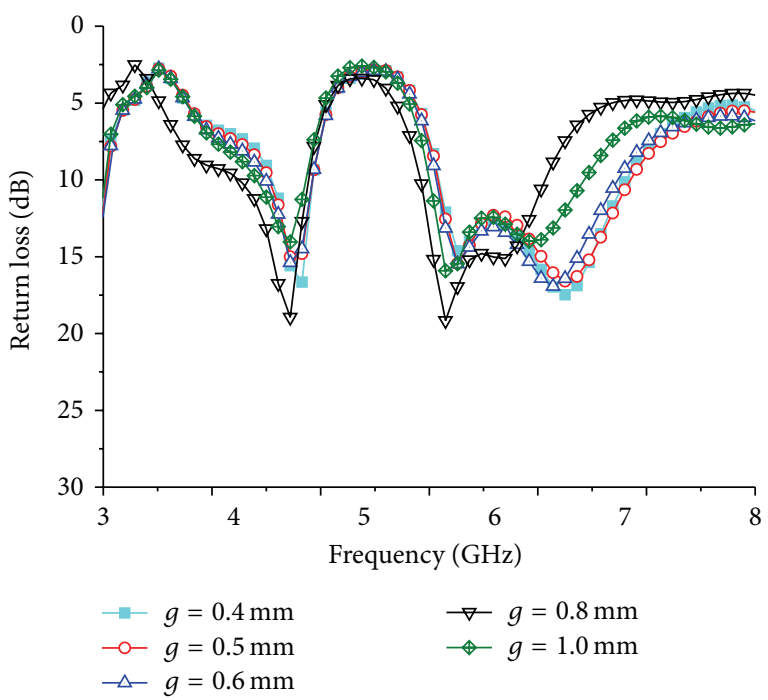

(b)

FIgURE 6: Parametric studies of (a) ground plane slot $W 3$ and (b) CPW gap $g$.

impedance mismatch between the two resonant modes. The best optimized value of this parameter is $L 1=15 \mathrm{~mm}$.

3.3. Current Distribution. Figure 8 illustrates the current distribution for $f 1, f 2$, and $f 3$ resonant modes to validate the above-mentioned results. Notably, the electric current distribution was chosen because it facilitated identifying the distribution characteristics of all the three modes. As shown in Figure $8(a)$, the excitation of $f 1$ was created by the half wave length current distribution along both pairs of symmetric strips and CPW fed a line with below side wall. A similar distribution was also observed for $f 2=5.20 \mathrm{GHz}$ as shown in Figure 8(b), except that the two (1/2) wave length currents patch were distributed along both upper slits and null point located there. Figure 8(c) indicated that the right hand side pair of strips is excited better that other side.

3.4. Radiation Efficiency and Axial Ratio. The radiation efficiency variation of the proposed antenna is shown in Figure 9. As shown in Figure 9, steady radiation efficiency at 96 to $87.4 \%$ was achieved between 3.19 and $3.88 \mathrm{GHz}$. On the other hand, in upper band section (4.93 to $6.06 \mathrm{GHz}$ ), the proposed antenna persuaded efficiency between 86.02 and $96.94 \%$. Figure 10 depicts the axial ratio of the proposed antenna. Generally, the axial ratio is considered to determine antenna polarization. If the value of the antenna in the achieved band is less than $3 \mathrm{~dB}$, then the antenna is called circular polarized. From the figure, it can be clearly stated 


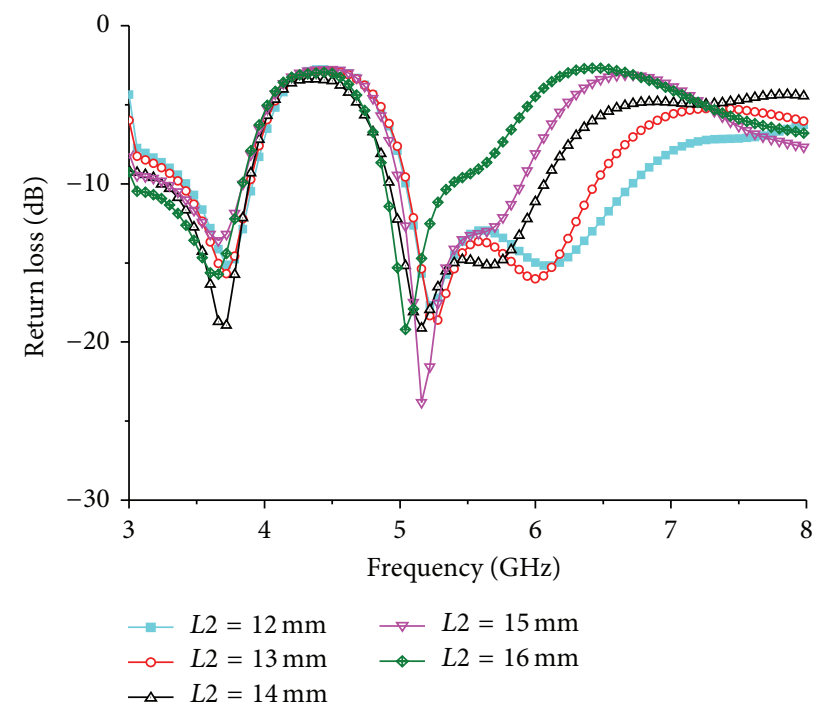

Figure 7: Parametric studies of the stunning stub $L 1$.

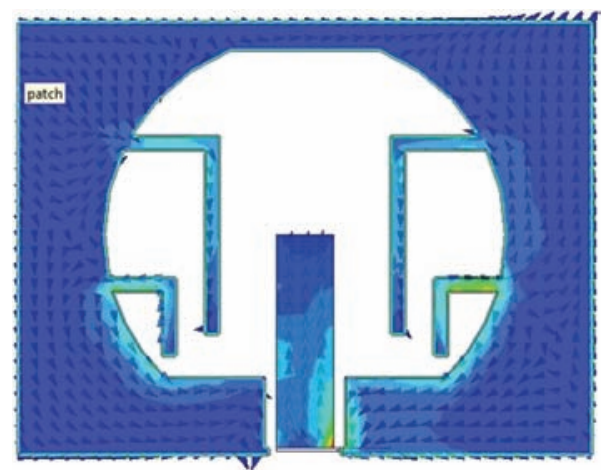

(a)

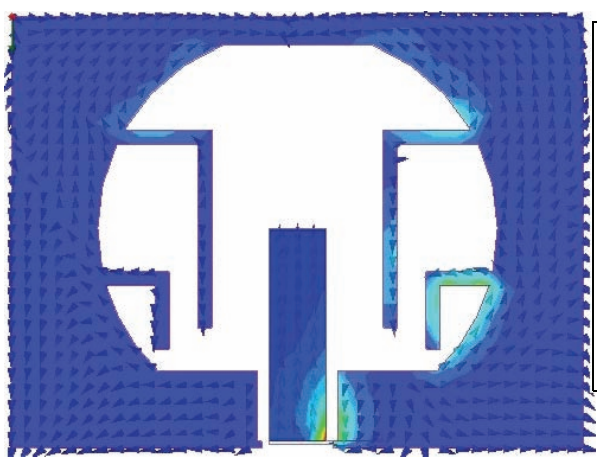

(c)

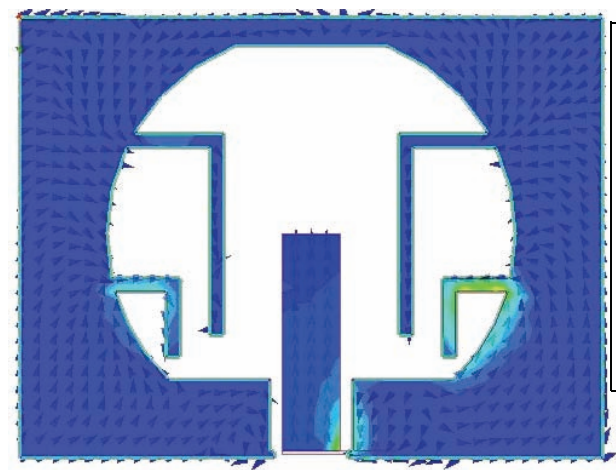

(b) $J_{\text {Surf }}$ (A_per_m)

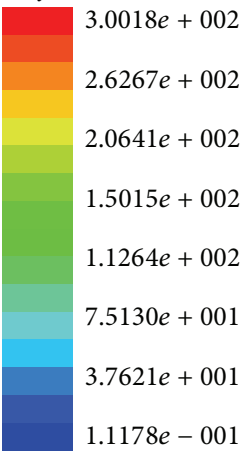

(d)

FIGURE 8: Simulated surface current distribution of proposed antenna at (a) $3.70 \mathrm{GHz}$, (b) $5.2 \mathrm{GHz}$, and (c) $5.8 \mathrm{GHz}$ (d) Scale.

that the value of the axial ratio is greater than $3 \mathrm{~dB}$ in the achieved band, which means the proposed antenna is linearly polarized.

3.5. Input Impedance. The input impedance and the voltage standing wave ratio are validated in Smith chart and input impedance which is shown in Figure 11. It can be understood that three of the resonances are in the $2: 1$
VSWR circle and input impedance is close to the standard $50 \mathrm{Ohm}$. The RX values in the Smith chart table represent the input impedance. Since, the curve has a tight resonant loop close to the centre of the Smith chart, which means that the proposed antenna provide a great enhancement for the impedance bandwidth, the markers $f_{c 1}, f_{c 2}$, and $f c 3$ represent the desired frequencies of the operating band. 
TABLE 2: Comparison between proposed and some existing antennas.

\begin{tabular}{lccc}
\hline Author & Dimension $(\mathrm{mm})$ & Bandwidth $(\mathrm{MHz})$ & Average peak gain $(\mathrm{dB})$ \\
\hline Proposed & $30 \times 40$ & 600,1040 & $3.23,5.93$ \\
{$[6]$} & $30 \times 35$ & $600,430,1300$ & $3.86,3.52,4.32$ \\
{$[16]$} & $29.5 \times 32$ & $500,1070,1010$ & $2.95,3.26,3.06$ \\
{$[24]$} & $40 \times 40$ & $300,280,790$ & $3.2,2.2,4.1$ \\
\hline
\end{tabular}

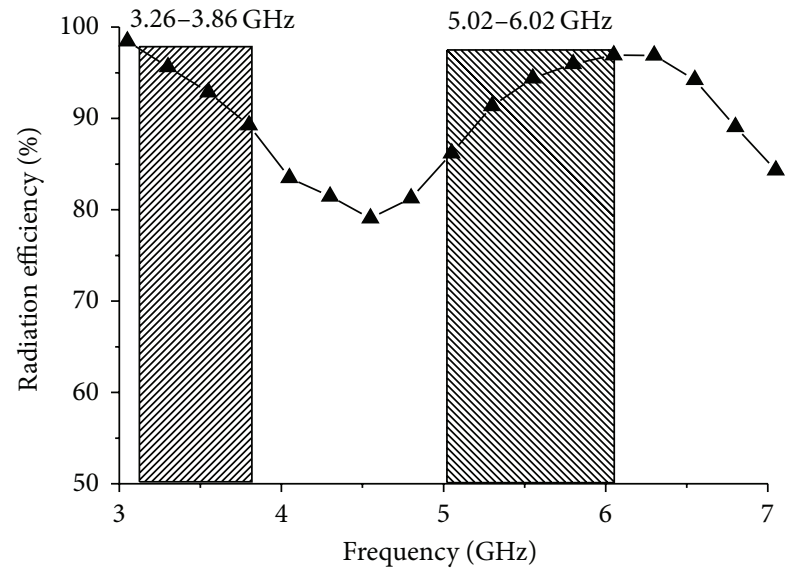

- Radiation

FIGURE 9: Radiation efficiency of the proposed antenna.

\section{Experimental Results and Discussion}

The simulated and measured return losses of the proposed antenna are presented in Figure 12, and a good agreement was established between the two results. In this figure, the $-10 \mathrm{~dB}$ impedance of both FL (lower band) and FU (upper band), centred at $3.67 \mathrm{GHz}, 5.22 \mathrm{GHz}$, respectively, were measured to be 16.34 and $23.18 \%$, respectively, confirming that the proposed antenna covers the Wi-Fi/WiMAX operating bands.

The radiation pattern of the proposed antenna was measured in a rectangular shape $5.5 \mathrm{~m} \times 5 \mathrm{~m} \times 3.5 \mathrm{~m}$ in an anechoic chamber. A double ridge guide horn antenna was used as reference antenna. The measuring antenna was placed face to face with the reference antenna. The photograph of the anechoic measurement chamber has been shown in Figure 13. Pyramidal shape electrically thick foam absorber has been used on the wall, ceiling, and floor with less than $-60 \mathrm{~dB}$ reflectivity at normal incidence. A turn table of $1.2 \mathrm{~m}$ diameter has been used to rotate the measuring antenna with specification, 1 RPM rotation speed, $360^{\circ}$ rotation angle connected with 10 meter cable between controllers. Agilent vector network analyzers ranges up to $20 \mathrm{GHz}$ have been used for measurement procedure. Figure 14 shows the measured far field radiation pattern of the proposed antenna at $3.67 \mathrm{GHz}, 5.22 \mathrm{GHz}$, and $5.8 \mathrm{GHz}$, respectively, in the $Y$ $Z$ (E plane) and $X-Z$ ( $H$ plane) which cover most of the major operating bands for Wi-Fi/WiMAX applications. The normalize copolarized (copolar) patterns of all three frequencies in the $X-Z$ plane show near typical omnidirectional radiations [25], and their corresponding cross-polarization

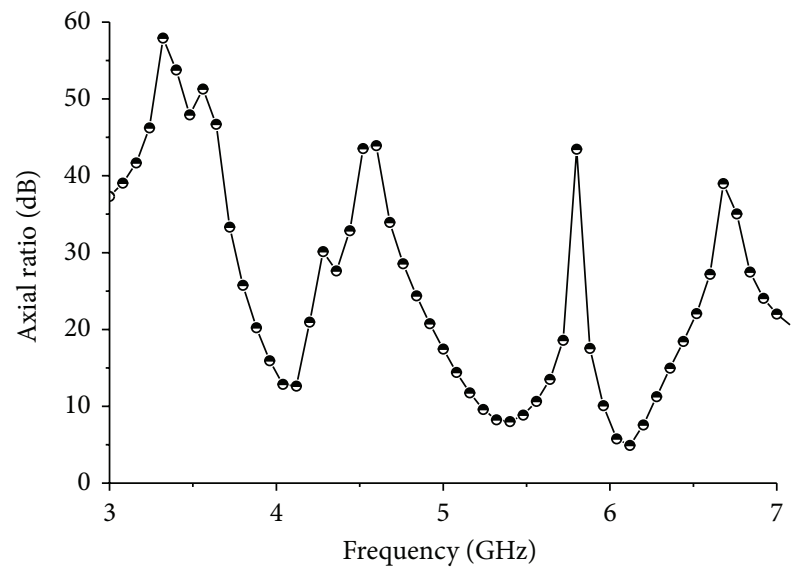

Figure 10: Axial ratio of the proposed antenna.

$(X-Z)$ plane patterns expose unidirectional patterns with low back lobe.

Finally, Figure 15 shows the achieved gains of the proposed antenna at various frequencies across the two operating bands. A standard three-antenna system with two identical horn antennas was used for gain measurement. The gains of the two identical horn antennas are known, and a gain measurement system that follows well-known equations was used for three antennas. From the following equations, the gain of the three antennas (under test) can be calculated because the gains of two horn antennas are known: $R$ is the distance between the two antennas and $P_{r}$ is the radiated power. Antenna 1 (horn) and Antenna 2 (horn):

$$
G_{1}+G_{2}=2 \log _{10}\left(\frac{4 \pi R}{\lambda}\right)+10 \log _{10}\left(\frac{P_{r 2}}{P_{r 1}}\right) .
$$

Antenna 1 (horn) and Antenna 3 (under test):

$$
G_{1}+G_{3}=20 \log _{10}\left(\frac{4 \pi R}{\lambda}\right)+10 \log _{10}\left(\frac{P_{r 3}}{P_{r 1}}\right) .
$$

Antenna 2 (horn) and Antenna 3 (under test):

$$
G_{2}+G_{3}=20 \log _{10}\left(\frac{4 \pi R}{\lambda}\right)+10 \log _{10}\left(\frac{P_{r 3}}{P_{r 2}}\right) .
$$

For directivity $D$, the following equation [26] is used in which $U$ is the radiation intensity and $P_{\text {rad }}$ is the total radiated power:

$$
D=\left(\frac{4 \pi R}{\lambda}\right) .
$$




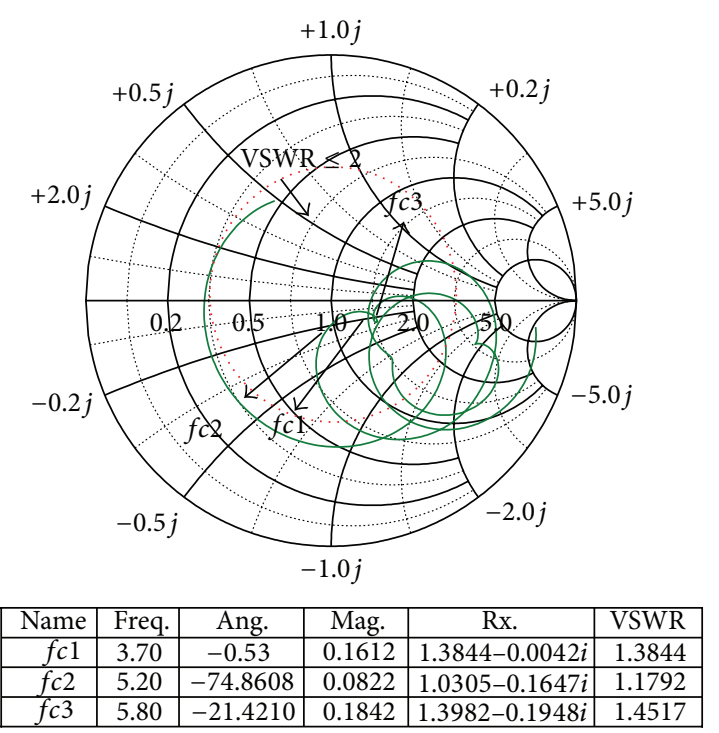

(a)

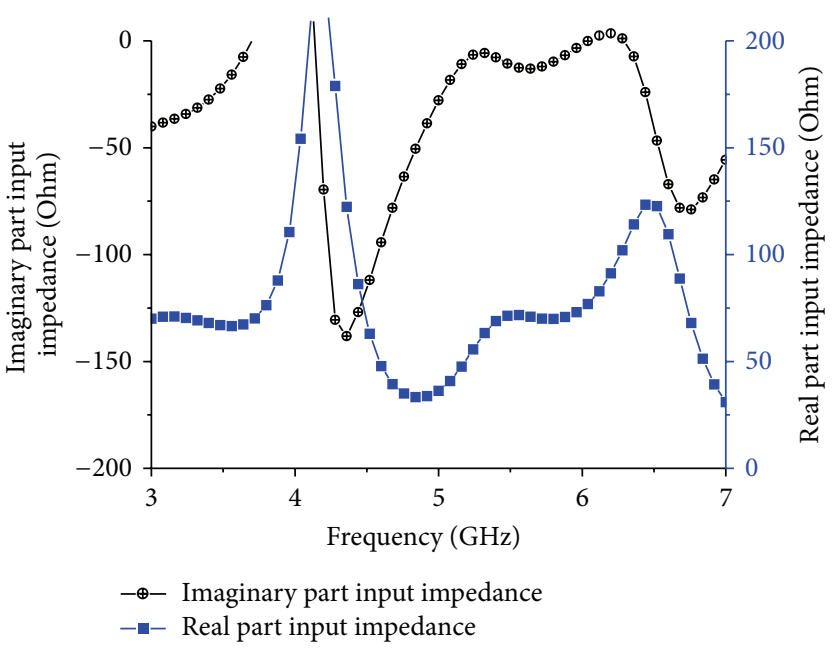

(b)

FIGURE 11: Proposed antenna (a), Smith chart, and (b) input impedance.

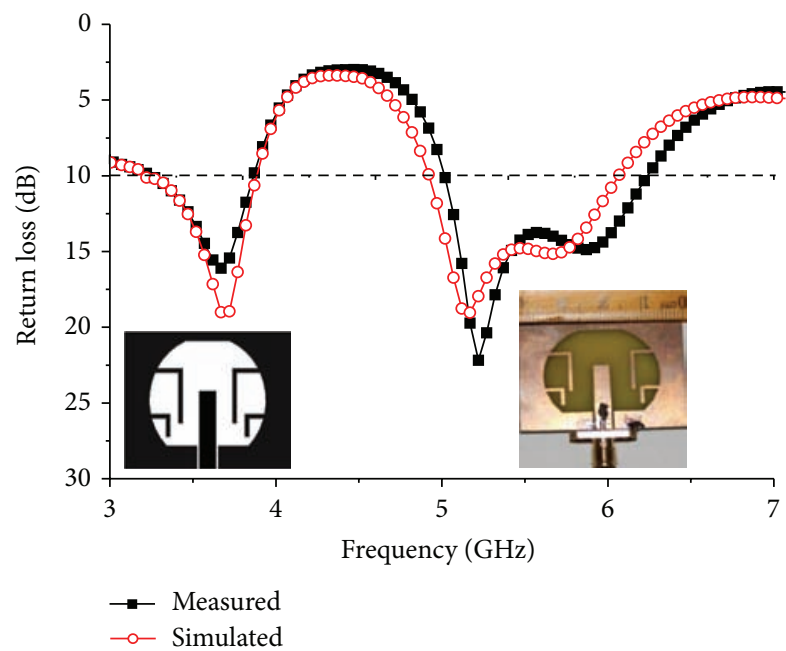

FIGURE 12: Simulated and measured return losses of the proposed antenna.

For the lower operating band of $3.26-3.86 \mathrm{GHz}$, the antenna gain is stable which varies from 3.19 to $3.22 \mathrm{~dB}$. The measured gain in the upper operating band of 5.02$6.26 \mathrm{GHz}$ varies from 3.20 to $6.45 \mathrm{~dB}$. The obtained average gains are about 3.23 and $5.93 \mathrm{~dB}$ for the lower and upper band, respectively. Hence, the radiation characteristics reveal that the proposed antenna is well suited to be embedded in the portable device for application in Wi-Fi/WiMAX applications.

Comparison between proposed and some existing antennas are tabulated in Table 2. From the table it is observed that the proposed antenna has been achieved with wider bandwidth and higher gain with smaller size compared to the reported antennas, although some of the reported

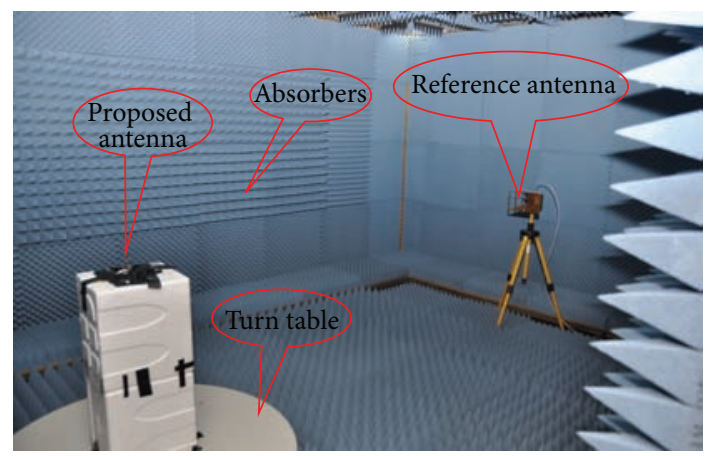

Figure 13: Anechoic chamber.

antennas have obtained a wide bandwidth and higher gain compromising the overall size.

\section{Conclusion}

A simple novel compact size $(0.24 \lambda \times 0.32 \lambda \times 0.128 \lambda$ at lower resonance frequency) CPW fed circular-slotted antenna with two symmetric pairs of planar inverted $L$ strips has been successfully designed and implemented. By using a rectangular patch and a symmetric pair of inverted $L$ strips (SPIL) the proposed antenna effectively excites three resonances and achieves a good input impedance matching which is suitable for the Wi-Fi $5.2 / 5.5 / 5.8 \mathrm{GHz}$ and WiMAX $3.3 / 3.5 / 3.7 / 5.8 \mathrm{GHz}$ operations. The design process and means of achieving the three resonant modes that moulded the lower (FL) and upper (FU) operating bands are studied in detail through the simulation software. Finally, the proposed antenna reveals wide impedance bandwidth for the two operating bands, good performance of gain, excellent resonance character, nice radiation pattern, and compact in 

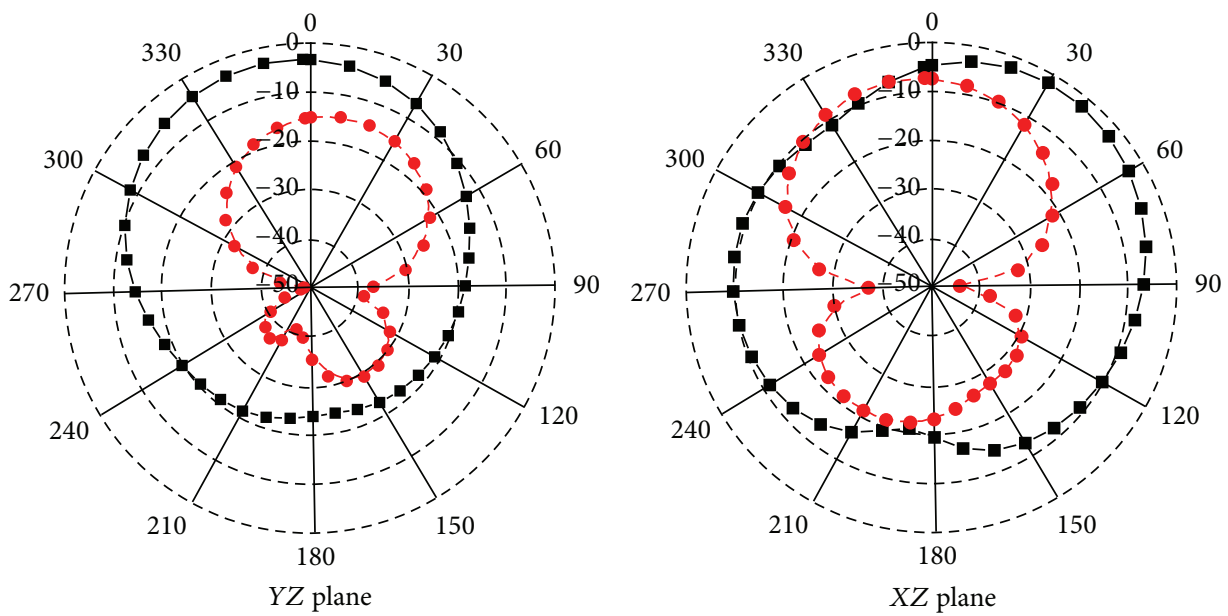

(a)
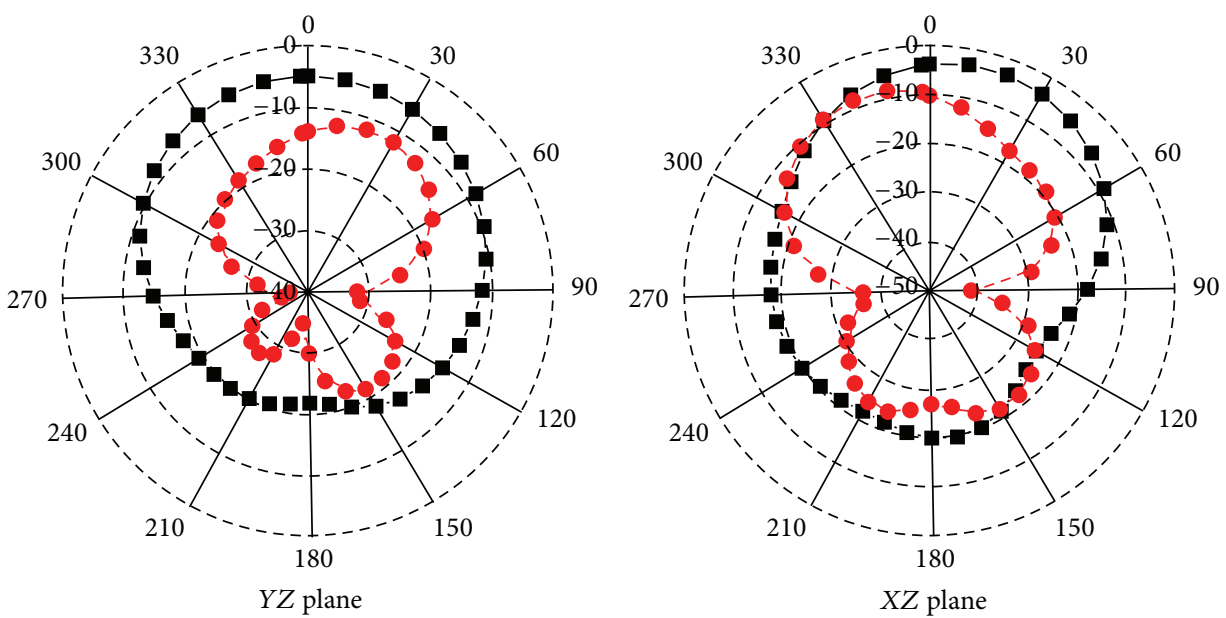

(b)
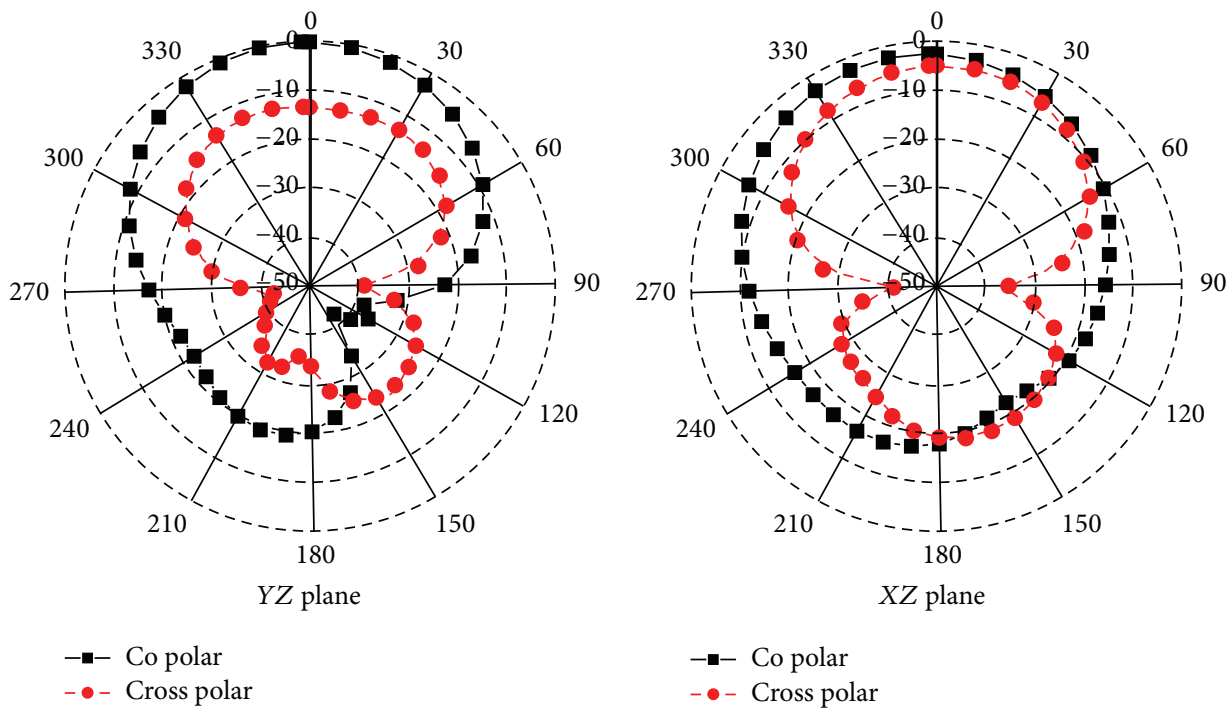

(c)

Figure 14: Radiation pattern of the proposed antenna at (a) $3.67 \mathrm{GHz}$, (b) $5.22 \mathrm{GHz}$, and (c) $5.8 \mathrm{GHz}$. 


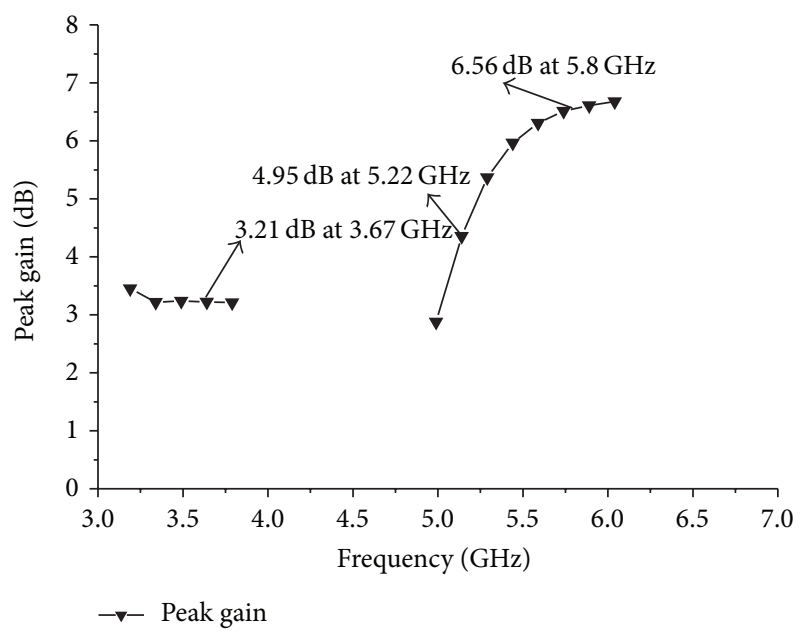

FIgURE 15: Peak gain of the proposed antenna.

size. Moreover, this antenna is fabricated on an inexpensive FR4; therefore, it is suitable for mass productions.

\section{Conflict of Interests}

The authors declare that there is no conflict of interests regarding the publication of this paper.

\section{References}

[1] A. T. Mobashsher, M. T. Islam, and N. Misran, "Wideband compact antenna with partially radiating coplanar ground plane," Applied Computational Electromagnetics Society Newsletter, vol. 26, no. 1, pp. 73-81, 2011.

[2] L. Liu, S. W. Cheung, R. Azim, and M. T. Islam, "A compact circular-ring antenna for ultra-wideband applications," Microwave and Optical Technology Letters, vol. 53, no. 10, pp. 2283-2288, 2011.

[3] R. Azim, M. T. Islam, N. Misran, S. W. Cheung, and Y. Yamada, "Planar UWB antenna with multi-slotted ground plane," Microwave and Optical Technology Letters, vol. 53, no. 5, pp. 966-968, 2011.

[4] J. J. Tiang, M. T. Islam, N. Misran, and J. S. Mandeep, "Slot loaded circular microstrip antenna with meandered slits," Journal of Electromagnetic Waves and Applications, vol. 25, no. 13, pp. 1851-1862, 2011.

[5] K. Yang, H. Wang, Z. Lei, Y. Xie, and H. Lai, "CPW-fed slot antenna with triangular SRR terminated feedline for WLAN/WiMAX applications," Electronics Letters, vol. 47, no. 12, pp. 685-686, 2011.

[6] L. Dang, Z. Y. Lei, Y. J. Xie, G. L. Ning, and J. Fan, "A compact microstrip slot triple-band antenna for WLAN/WiMAX applications," IEEE Antennas and Wireless Propagation Letters, vol. 9, pp. 1178-1181, 2010.

[7] C. Sim, F. Cai, and Y. Hsieh, "Multiband slot-ring antenna with single-and dual-capacitive coupled patch for wireless local area network/worldwide interoperability for microwave access operation," IET Microwaves, Antennas \& Propagation, vol. 5, pp. 1830-1835, 2011.

[8] C.-Y. Sim and F.-R. Cai, "Rectangular slot antenna design with two L-shaped slits for WLAN/WiMAX applications,"
Microwave and Optical Technology Letters, vol. 53, no. 5, pp. 987991, 2011.

[9] J.-Y. Jan and L.-C. Wang, "Printed wideband rhombus slot antenna with a pair of parasitic strips for multiband applications," IEEE Transactions on Antennas and Propagation, vol. 57, no. 4, pp. 1267-1270, 2009.

[10] J. N. Lee, J. H. Kim, J. K. Park, and J. S. Kim, "Design of dual-band antenna with U-shaped open stub for WLAN/UWB applications," Microwave and Optical Technology Letters, vol. 51, no. 2, pp. 284-289, 2009.

[11] J. Pei, A.-G. Wang, S. Gao, and W. Leng, "Miniaturized triple-band antenna with a defected ground plane for WLAN/WiMAX applications," IEEE Antennas and Wireless Propagation Letters, vol. 10, pp. 298-301, 2011.

[12] J.-W. Wu, H.-M. Hsiao, J.-H. Lu, and S.-H. Chang, "Dual broadband design of rectangular slot antenna for 2.4 and $5 \mathrm{GHz}$ wireless communication," Electronics Letters, vol. 40, no. 23, pp. 1461-1463, 2004.

[13] Z. Zhang, M. F. Iskander, J.-C. Langer, and J. Mathews, "Dualband WLAN dipole antenna using an internal matching circuit," IEEE Transactions on Antennas and Propagation, vol. 53, no. 5, pp. 1813-1818, 2005.

[14] M. T. Islam, M. Moniruzzaman, N. Misran, and M. N. Shakib, "Curve fitting based particle swarm optimization for uwb patch Antenna," Journal of Electromagnetic Waves and Applications, vol. 23, no. 17-18, pp. 2421-2432, 2009.

[15] R. Azim, M. T. Islam, and N. Misran, "Printed planar antenna for wideband applications," Journal of Infrared, Millimeter, and Terahertz Waves, vol. 31, no. 8, pp. 969-978, 2010.

[16] J. Cao, X. Zhao, C. Liu, and L. Yan, "A planar compact tripleband monopole antenna for wlan/wimax applications," Progress in Electromagnetics Research Letters, vol. 29, pp. 15-23, 2012.

[17] Y. Xu, Y. -C. Jiao, and Y. -C. Luan, "Compact CPW-fed printed monopole antenna with triple-band characteristics for WLAN/WiMAX applications," Electronics Letters, vol. 48, pp. 1519-1520, 2012.

[18] P. Shu and Q. Feng, "Compact tri-band monopole antenna with a parasitic E-shaped strip for WLAN/Wimax applications," Progress in Electromagnetics Research C, vol. 32, pp. 53-63, 2012.

[19] H.-D. Chen, J.-S. Chen, and Y.-T. Cheng, "Modified invertedL monopole antenna for 2.4/5 GHZ dual-band operations," Electronics Letters, vol. 39, no. 22, pp. 1567-1569, 2003.

[20] Q.-X. Chu and L.-H. Ye, "Design of compact dual-wideband antenna with assembled monopoles," IEEE Transactions on Antennas and Propagation, vol. 58, no. 12, pp. 4063-4066, 2010.

[21] R. Azim, M. T. Islam, and N. Misran, "A planar monopole antenna for UWB applications," International Review of Electrical Engineering, vol. 5, no. 4, pp. 1848-1852, 2010.

[22] C.-Y. Pan, T.-S. Horng, W.-S. Chen, and C.-H. Huang, "Dual wideband printed monopole antenna for WLAN/WiMAX applications," IEEE Antennas and Wireless Propagation Letters, vol. 6, pp. 149-151, 2007.

[23] A. Mousazadeh, M. Naser-Moghaddasi, F. Geran, S. Mohammadi, and P. Zibadoost, "Broadband CPW-Fed circularly polarized square slot antenna with arc-shaped and invertedL grounded strips," Applied Computational Electromagnetics Society Journal, vol. 28, pp. 314-320, 2013.

[24] Q. Zhao, S. X. Gong, W. Jiang, B. Yang, and J. Xie, "Compact wide-slot tri-band antenna for WLAN/WiMAX applications," Progress In Electromagnetics Research Letters, vol. 18, pp. 9-18, 2010. 
[25] M. Samsuzzaman, M. T. Islam, and J. S. Mandeep, "Parametric analysis of a glass-micro fibre-reinforced PTFE material, multiband , patch-structure antenna for satellite applications," Optoelectronics and Advanced Materials, vol. 7, pp. 760-769, 2013.

[26] C. A. Balanis, Antenna Theory: Analysis and Design, WileyInterscience, 2012. 

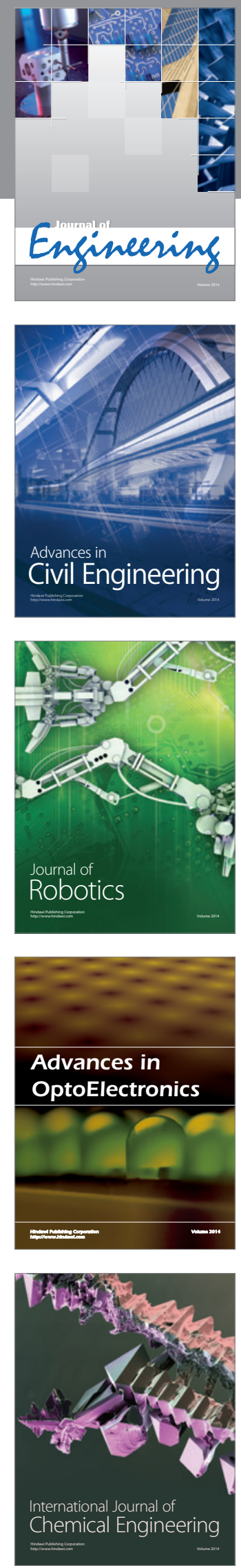

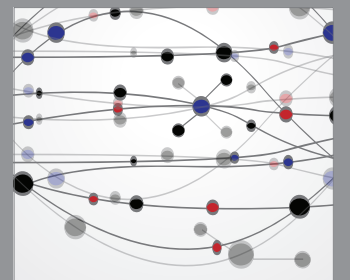

The Scientific World Journal
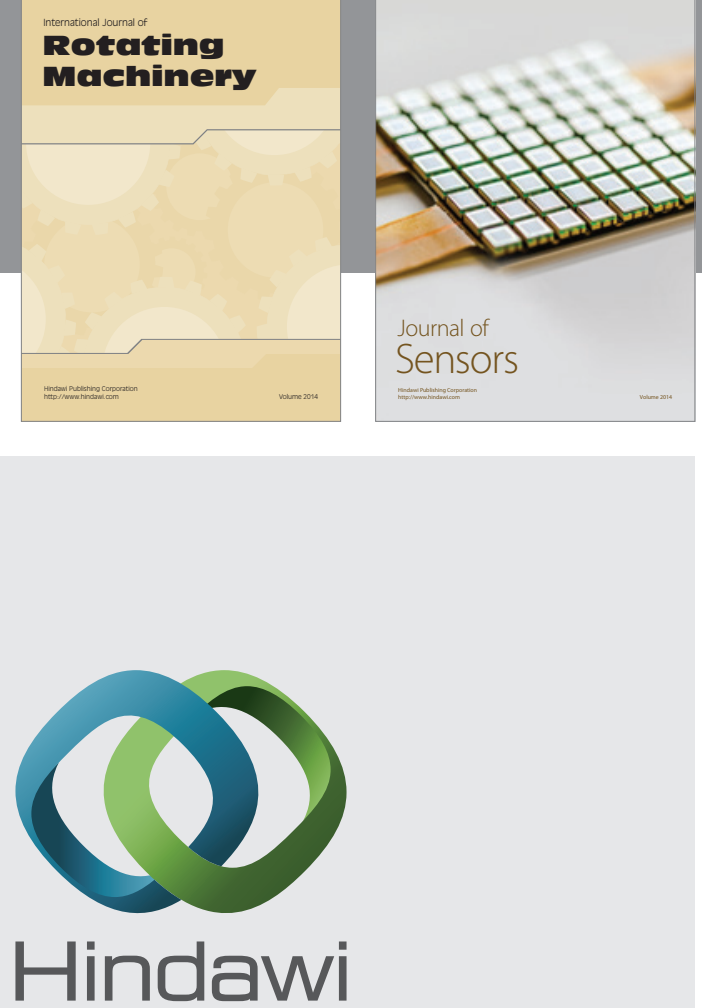

Submit your manuscripts at http://www.hindawi.com
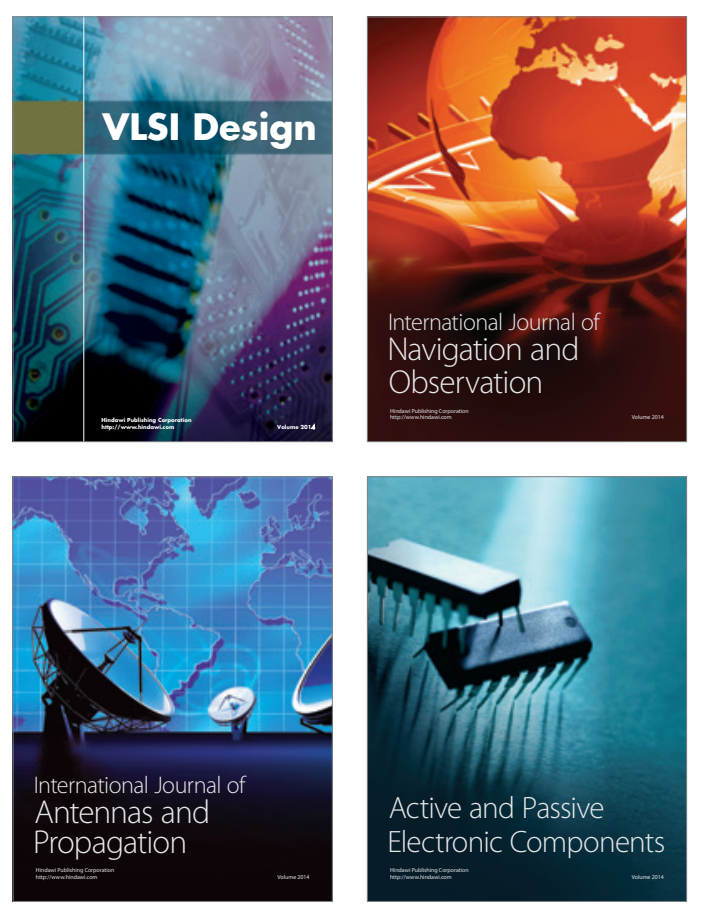
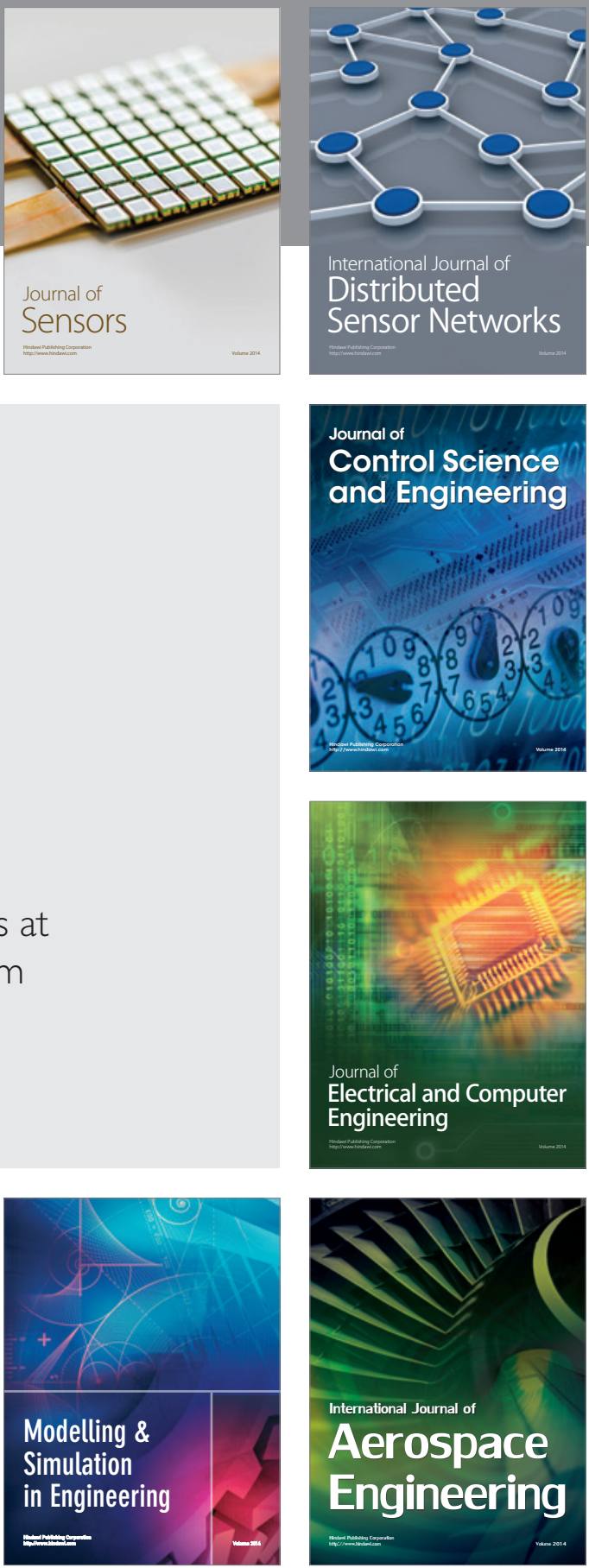

Journal of

Control Science

and Engineering
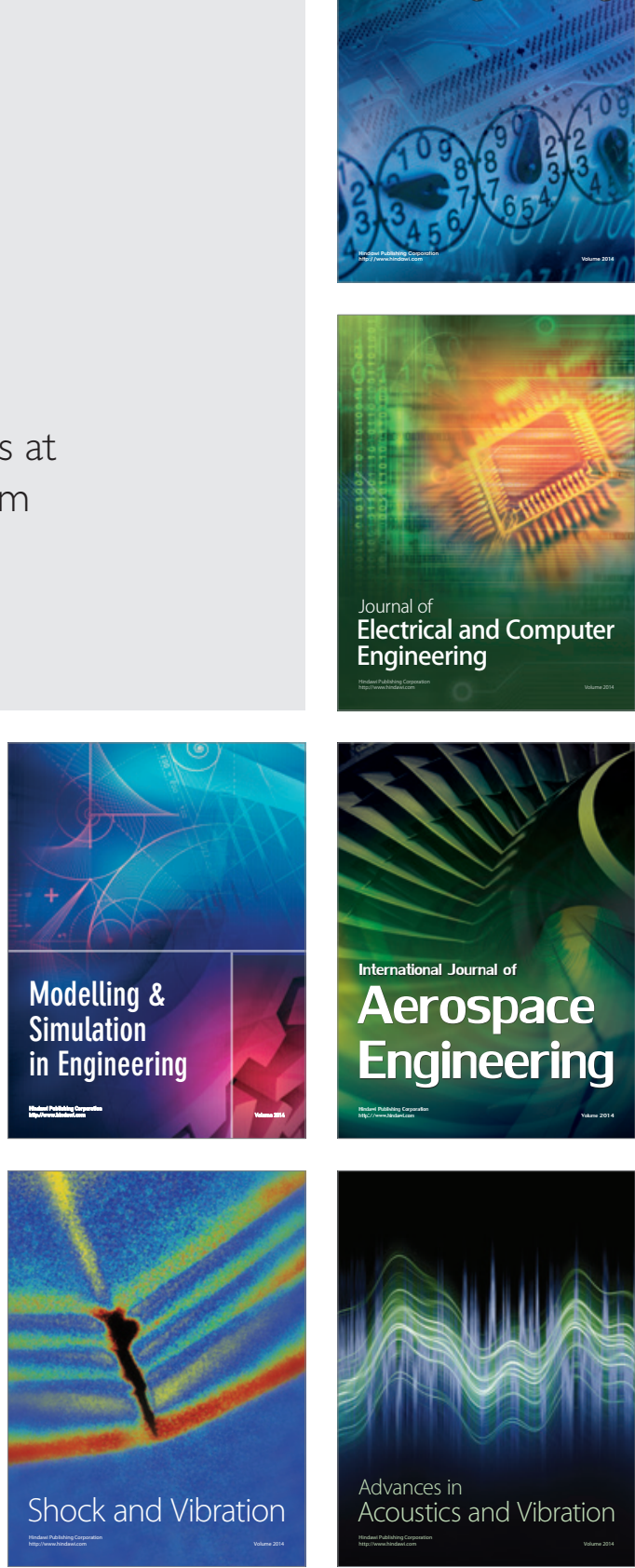